Sciendo

\title{
Wittgenstein on Mathematical Identities
}

André Porto

UFG - Brazil

Disputatio Vol. 4, No. 34

December 2012

DOI: $10.2478 /$ disp-2012-0031

ISSN: 0873-626X 


\title{
Wittgenstein on Mathematical Identities
}

\author{
André Porto \\ UFG - Brazil \\ BIBLID [0873-626X (2012) 34; pp. 755-805]
}

\section{I - Introduction}

This paper offers a new interpretation for Wittgenstein's treatment of mathematical identities. As it is widely known, Wittgenstein's mature philosophy of mathematics includes a general rejection of abstract objects. On the other hand, the traditional interpretation of mathematical identities involves precisely the idea of a single abstract object - usually a number -named by both sides of an equation. We may follow (QUINE, 1960, p. 114) and take identity as a relation directly between terms or we may prefer Frege's ideas and insist on its being mediated by senses (FREGE, 1977, p. 56). Either way, we normally take these statements as crucially involving an appeal to a single object as the referent of both relata, weather they are senses or terms. But if we completely let go the idea of this abstract pivot, how could we possibly make sense of such mathematical statements? What would sentences such as " $2+3=5$ " be about, if they were not about numbers?

This is where the idea of back and forth correction comes in. We propose this terminology to refer to Wittgenstein's notorious revamping of the traditional construal of (mathematical) identities. As we shall see, this new interpretation of equations also touches upon at least two other central elements of his philosophy of mathematics. The first element is his treatment of mathematical generality (and his rejection of quantifiers ${ }^{1}$ ). The second one is his handling

1 It is perhaps important to remember here that Wittgenstein is not alone in this rejection of quantifiers. Skolem (SKÖLEM, 1952,, p. 120) also singles them

Disputatio, Vol. IV, No. 34, December 2012 
of statements involving Infinity. Taken together, his treatment of mathematical identities, of generality and infinity, make up a large portion of Wittgenstein's approach to mathematics, a proposal which is distinct both from the classical realistic proposal and from the constructive one, centered on the notion of potentiality.

Most features of this alternative position regarding mathematics are still not widely known and thus his whole proposal remains unacknowledged by researchers on the foundations of mathematics at large. ${ }^{2}$ We believe this sad situation is in part due to the difficulty of dissociating Wittgenstein's ideas from his very idiosyncratic jargon, thus making them available to a wider audience, and in part due to our sheer lack of understanding of the key logical elements of that approach.

Our article will be divided into three parts. We will begin by a general discussion of some other very general approaches to mathematical identities. Our goal will be a negative one. Throughout our paper we will use these other alternative handlings of identities in order to contrast them with Wittgenstein's proposals. In the second part of our paper we will focus on Wittgenstein's extensive analysis of a special type of mathematical identities, the ones involving recurring decimals. Two main ideas will be introduced here. The first one will be his critique of the elision dot's notation. The second will be his insistence on the introduction of the syntactical operation of iterated copying on the right side of that kind of equation. We will dedicate the entire final section of our article to Wittgenstein's treatment of mathematical identities as back and forth correction. This will involve a generalization of the treatment of recurring decimal's identities to other kinds of mathematical identities.

Before we move on to the main argument of the paper, a note on exegetical claims. Wittgenstein's writing is very extended and varied. There is no agreement on just what he said (or implied), and when. Many times we don't even know if he is the one doing the out as the key source of the fundamental "faults" afflicting classical mathematics.

2 Despite important monographs on the theme, such as (WRIGHT, 1980), (SHANKER, 1987), (STENLUND, 1990), (FRASCOLLA, 1994) and (MARION, 2008) 
talking, or his ever present interlocutor. Any bolder reconstruction such as the present one runs the risk of appearing to be more than just that: plain misattribution to him of views he never sustained. As we said before, our main objective is to try to view his philosophy from without, offering as wide a perspective as possible of his work within the foundations of mathematics. To be able to do so with a little more freedom, we will follow an option that has become common ever since Kripke wrote (KRIPKE, 1972). ${ }^{3}$ We will drop any substantial exegetical claims. We still try to offer (what we take to be) the appropriate quotes, but the reader is free to disregard them if he or she thinks they are not nearly enough to sustain our exegetical claims.

\section{The Operational Reading of Mathematical Identities}

Let us take a simple mathematical identity such as

$$
2+3=5
$$

If we lay aside all our mathematical and logical sophistications aside and, say, go back to an elementary school reading of such statements, it appears natural to take these identities as being directed. We start from the left, by operating with the numbers 2 and 3 - we add them - and then we obtain, or produce, the result, in the right hand side of the equation, the number 5 . In such a reading, the two sides of the equation are not on the same level. The interpretation is not "flat". It has a (main) orientation: we start from the left side and generate the result on the right.

$$
2+3 \rightarrow 5
$$

This is the reading that is preserved, of course, in a recursive interpretation of (1). By utilizing the well known definition of addition

$$
\left\{\begin{array}{l}
a+0=a \\
a+s n=s(a+n)
\end{array}\right.
$$

3 Cf. also (STENLUND, 1990, p. viii) 
we could even represent this operation as a sort of "short hand" for series of step by step "externalizations" of the unary operation of "successor for":

$$
\begin{gathered}
s s 0+s s s 0 \\
s(s s 0+s s 0) \\
s s(s s 0+s 0) \\
s s s(s s 0+0) \\
s s s s 0
\end{gathered}
$$

This way of viewing identities is precisely the one advocated by intuitionists such as Martin-Löf (MARTIN-LÖF, 1984, p. 71). In such readings, there is an intrinsical unbalance between the result, sssss 0 , and the initial left hand side expression, ss $0+s s s 0$. This latter expression is not in canonical notation. The very idea of an "operation" is explained by appealing to the fundamental distinction of canonicity and non-canonicity (DUMMETT, 1991, p. 175; MARTIN-LÖF, 1987; PRAWITZ, 1977). We could even say that ss $0+$ sss 0 denotes an number, but only because this non-canonical expression could be transformed into a canonical expression, the expression SSSSS0. This is the semantical intuitionist's view of the notion of "number". ${ }^{4}$

Before we leave behind the constructive approach to arithmetical identities and move on to Frege's ideas concerning such statements, let us quickly draw our attention to one important ingredient of the constructive approach to mathematics, an aspect that laid somehow hidden in our seemly innocuous modal expression "could be transformed" (in the last sentence of our previous paragraph). The duty a semantical intuitionist expects this modal to perform is anything but trivial and innocuous, philosophically speaking. The problem is: any non canonical expression can succeed in denoting a number only by appealing to its "possible transformation" into a canonical expression of the form " $s \ldots s 0$ ". It's true that one can prove,

4 We will only consider in this paper the contemporary type of intuitionism of Dummett, Prawitz and Martin-Löf, usually known as "Semantical Intuitionism”. We will not discuss the classical intuitionism of, say, Brouwer. 
within an intuitionistic system such as Martin-Löf's, that these operations are "possible". But, for numerical expressions involving "very large numbers" (say, as $10^{10^{10}}$ ), how possible is this posited possibility?

The idea of having the very semantics of mathematics depend on these grossly idealized possibilities (the "impossible possibilities") appears suddenly as philosophically fishy. One should not forget here also that the central argument for the intuitionistic assault on classical mathematics had to do precisely with criticisms regarding idealized possibilities such as these:

The fact that quantification over an infinite totality shares so much in common with quantification over a finite one tempts us to overlook the crucial difference from the case in which we are quantifying over a finite totality which we can survey, namely that we do not have, even in principle a method of determining the truth-value of quantified statement by carrying out a complete inspection of the elements of the domain and checking for each one, whether the predicate applies (DUMMETT, 1977, p. 6). ${ }^{6}$

Thus it should not come as a surprise that authors, such as Crispin Wright, should pointed out that "arguments essentially analogous to those which the mathematical Intuitionists ... use to support their revisions of classical logic" could now be redirected against the intuitionists themselves (WRIGHT, 1993, p. 107). ${ }^{7}$ We will come back to this point latter on.

\section{Frege's "flat" reading of identities}

For a platonist such as Frege, a number is a number, not because we can prove it to be so (within some formal system), but because

5 This is precisely the task of N-elimination rules in Martin-Löf's system (MARTIN-LÖF, 1984, p. 71)

6 My italics.

7 For more extensive discussions of this point, cf. (MARION, 2008, p. Chap 8; STENLUND, 1990, pp. 146-51) 
mathematical reality is such. Numbers are abstract objects whose existence is conceptualized as being completely independent of any epistemological act such as a demonstration. Accordingly, in this classical reading of identities anticipated in the beginning of our paper, $2+3$ is equal to 5 simply because both " $2+3$ " and " 5 " name the same object. This naming relation is not tributary to any more fundamental operation, such as the successor function.

As we know, Frege (and Russell) famously advocated a purely cardinal view of numbers as equivalence-classes generated by the equinumero-sity-relation (FREGE, 1964, p. 78). In sharp contrast to the ordinal approach latter favored by the intuitionists, any number such as the number 3 is not seen as the result of, say, there applications of the operation successor to an initial object 0

$$
s(s(s(0)))
$$

but as an enormous class of all "triples".

Thus, in contrast to the previous, constructive alternative we presented before, in the classical, fregean view, a mathematical identity is something completely "symmetrical". There is no prior notion of a "result" (of an operation). "5" names an abstract object in precisely the same way as " $2+3$ ". And since both of them happen to name the same abstract object, the statement (1) is true. 5 is "as much equal" to " $2+3$ " as vice-versa, there is not a more fundamental "direction" here. ${ }^{8}$

Following (BAKER \& HACKER, 1988, p. 22) I propose to call this classical view of identities "flat". This is important because, as we will see, contrary to what one might have expected, even thought Wittgenstein does insist on introducing the notion of "operation", his reading of identities is completely flat. More than that, as Backer and Hacker correctly pointed out, this "flat view" is characteristic not only of his interpretation of identities but of his

8 We could of course insist that the name " 5 " is simple and that " $2+3$ " is a complex name, but this would appeared to be system-dependent. We would still need some sort of "transcendent" or "metaphysical" notion of simplicity here to mark out the difference. 
whole approach to mathematics, all the way from the Tractatus on (WITTGENSTEIN, 1961, p. 6.127). This is but one of the fundamental differences between Wittgenstein and the constructivists. ${ }^{9}$

One has to be careful here, thought. Wittgenstein reading of (1) is flat in the sense of its not being directed. But that does not mean that Wittgenstein endorses the classical "triangular" view of mathematical identities (as true when both its side-names denote the same abstract object).

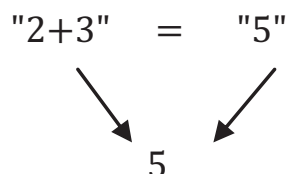

He never did accept the triangular construal. There are two notions of identity in the Tractatus. One of them is the "ontological", it is asserted directly of objects, not of names or senses of objects. But this notion degenerates into mere self-identity, $[\lambda x \cdot x=x]$ (WITTGENSTEIN, p. 5.5303). The other one is mere synonymity (WITTGENSTEIN, p. 6.2323). Neither of them, though, is the classical, "triangular" notion. In fact, as we've anticipated before, Wittgenstein all together rejected any idea of an "abstract object" (acting as pivot for identities). As we pointed out, for him mathematical statements are not about any such "abstract entities", such as numbers. And so, per force, his rendering of mathematical identities could not possibly be the classical one.

\section{II - Recurring Decimals}

\section{Criticism of the elision dots' notation}

Following Wittgenstein, let us change our main example from the simple equation " $2+3=5$ " to something a little bit more complicated: identities involving infinite recurring decimals such as:

$$
1 \div 7=0.142 \ldots
$$

9 Another important difference is his rejection of any notion of "in principle possibility" and accordingly of any idea of "potential infinity". 
The reason for Wittgenstein focusing on these (rather plain) mathematical identities is quite apparent. In (2) we have pretty much the first (and simplest) example of statement involving infinity in our elementary mathematical education. In a typical strategy for him, the philosopher finds here a thoroughly perspicuous example on which to focus his investigation. In examples such as this, he has all the key elements of some general problem he is interested in without any inessential technical complexities. As we will see, in the case of recurring decimals, these ingredients include mathematical identities and abstract objects, generality and of course, infinity. ${ }^{10}$

The first element Wittgenstein is interested in his surprisingly long and elaborate discussions on recurring decimals ${ }^{11}$ is of course the elision dots' notation. This is a theme that absorbed him thorough out his matured philosophy of mathematics. We find several examples of this in his intermediary masterwork, the Big Typescript:

What does one see " $1,1+1,1+1+1, \ldots$ " as?

As an inexact form of expression. The dots are like additional numerals, but ones that are indistinct. As if one stopped writing down numerals because to be sure one can't write them all down. , but as if they were all there in a kind of box.

The dots in " $1+1+1+1 \ldots$ " are nothing but four little dots: a sign for which it must be possible to state certain rules. (Namely, the same rules as for the sign "etc, ad inf.") This sign does imitate an enumeration in a way, but is isn't an enumeration. And that most likely the rules that apply to it agree up to a point, but not completely, with thoes that apply to an enumeration. (WITTGENSTEIN, 2005, pp. $260,257-8)$

Even as late as in the Philosophical Investigations we find him saying:

10 The infinity ingredient becomes apparent if we recast (2) as

$$
1 \div 7=\sum_{n=1}^{n=\infty} \frac{142857}{(1000000)^{n}} .
$$

We will talk about the generality component later.

11 Cf. (WITTGENSTEIN, 1975, pp. 223-34), (WITTGENSTEIN, 2005, pp. 466-7), (WITTGENSTEIN, 1979, pp. 183-6) and (WITTGENSTEIN, 1976, pp. 122-30) 
We should distinguish between the "and so on" which is, and the "and so on" which is not, an abbreviated notation. "And so on ad inf." is not such an abbreviation. The fact that we cannot write down all the digits of $\mathrm{p}$ is not a human shortcoming, as mathematicians sometimes think. (WITTGENSTEIN, 2005a, pp. § 208, p 71)

Wittgenstein's worries about the elision dot's notation are clearly semantical. In his words, this notation "imitates an enumeration", but it is clearly not one. It's rules agree to a list only "up to a point". So, what are exactly the rules that govern it? To understand better Wittgenstein's point here it is best to go back to Frege's ideas on identity statements (and also to Kripke's ideas about "non-standard" continuation of infinite series). To anticipate a little, Wittgenstein complains that the identity such as (2) is ill formed! But let us follow his arguments step by step.

" $1 \div 7=0.142 \ldots$... is an identity. So, according to (FREGE, 1977, p. 43) one should find nominal expressions on both sides of the relational predicate " $=$ ". " $1 \div 7$ " is surely a fregean name (albeit a composed one), but what about " 0.142 ...”? Is "0.142 ...” a singular term? Once again invoking Frege, we could say: if " $0.142 \ldots$..." is to function as a singular term, it has to succeed in denoting one and only one object. According to Frege, existence, the first requirement for a nominal expression is not so essential. In a famous passage of On Sense and Reference, he is notoriously willing to accept "Odysseus" as a name, even though it has no reference (FREGE, 1977, p. 62). But as to the second requirement, unicity of denotation, he was never willing to relax it. If a referring expression is to function as a singular term, it has to denote at most one single object.

It is Frege's second, more crucial requirement, that, according to Wittgenstein, " $0.142 \ldots$..." is not capable of satisfying. To see this one has only to consider some "non-standard" possible continuations for "0.142 ...” (KRIPKE, 1972, p. 16). The standard continuation would, of course, be " $0.142857142 \ldots$... But, what about alternative continuations such as " $0.1421142124 \ldots$... or " $0.1422142224 \ldots$...? Which of them is the (correct?) continuation of " 0,142 ..."? This is important when we consider the following identities: 


$$
\begin{aligned}
& 1241 \div 9999=0.124 \ldots \\
& 1242 \div 9999=0.124 \ldots \\
& 1243 \div 9999=0.124 \ldots
\end{aligned}
$$

Would all these statements be true? All of them simultaneously true (together with (2))? And so, by transitivity, should we conclude that:

$$
1241 \div 9999=1242 \div 9999=1243 \div 9999=1 \div 7 ?
$$

Wittgenstein's worries are clear: "0,142 ..." could not possibly be a singular term, a numeral, just because if there were such a term, it would (ambiguously) denote a infinitude of different numbers! In fact the most reasonable course would be simply to abandon the idea of " $0.142 \ldots$... as a singular term. According to this later option, "0.142 ..." would not be a numeral, "0.142 ..." would be a general term! It's meaning could be elucidated as something like:

"any infinite decimal fraction beginning by the digits '0', '1', '2' and '4'”

Of course if we were to reclassify $0.142 \ldots$... as a general term, another difficulty would soon come up. What would a general term be doing flanking an identity statement such as (2)? Once again we are back against fregean requirements. What would be the truth conditions of these ("strange") identities? As we anticipated before Wittgenstein concludes that we should simply discard all such statements as being ill-formed.

The elision dot notation has elude us with its idea of some "additional, hidden digits" hiding in the infinite continuation of " 0.142 ..." which would fix the correct intended denotation, finally transforming it into a singular term, a numeral. The philosopher writes:

The incorrect conception of the word "infinite", and of the role of "infinite expansions" in the arithmetic of the real numbers, seduces us into thinking that there is a uniform notation for irrational numbers (namely the notation of the infinite extension, e.g. of infinite decimal fractions) (WITTGENSTEIN, 2005, p. 498) 
Thus, the passage we quoted above, from the Philosophical Investigations: "We should distinguish between the "and so on" which is, and the "and so on" which is not, an abbreviated notation." "0.142 ..." is not an abbreviated notation. It is not even a numeral. And, as we will see, we should reject " $0.142 \ldots$ " as a numeral, not because of any epistemological qualms about infinity, such as the Constructivist's, but merely due to semantical requirements, the necessity of clearly maintaining the distinction between general and singular terms!

\section{The missing operation}

Let us return to our discussion of identities involving recurring decimals, of an identity such as (2) $1 \div 7=0.142 \ldots$. There is an obvious remedy for our difficulty: we are here dealing with a recurring decimal. There is a cycle involved. So in this case we could use this cycle to finally fix our notation and obtain a singular term. ${ }^{12}$ There are many ways to do that. A particularly simple one is the traditional "cycle dot notation", used in some analysis' books:

$$
1 \div 7=0 . \dot{1} 4285 \dot{7}
$$

For Wittgenstein, differently from statements such as (2), (2') is obviously well formed. But just as in these analysis' books that employ the cycle dot notation, it is very important for him, as it is for them (GARDINER, 1982, p. 67), to point out that numerals such as $0 . \dot{1} 4285 \dot{7}$ have very different mathematical properties than those of ordinary numerals such as "0.142857". A well known example would of course be:

$$
0 . \dot{9}=1
$$

12 Any mathematician is bound to be worried. Our "remedy" has clear revisionary implications here. How would we deal with all the other (much more "important") cases? Wittgenstein's proposals are clearly revisionary, there is no doubt about that. They do not "leave mathematics as it is". But let us stay calm and follow his proposals step by step. There are many further elements that have to be drawn into our scenario. 
Wittgenstein stresses the differences in the "grammars" of these different kinds of numbers:

The confusion in the conception of the "actual infinite" arises from the unclear concept of "irrational number", that is, form the fact that constructs that are logically quite different are called "irrational numbers" without any clear limits being given to the concept. (WITTGENSTEIN, 2005, p. 496)

The discovery of the periodicity is really the construction of a new symbol and a new calculus.

$$
\begin{aligned}
& 1 / 3=\text { " } 0 . \dot{3} \text { " is not the same kind of thing as } \\
& \text { " } 1 / 2=0.5 " ;
\end{aligned}
$$

" $0 . \dot{3}$ " is not the result of a division (quotient) in the same sense as 0.375. (WITTGENSTEIN, 2005, p. 446)

One can say of the sign " 0.3 that it is not an abbreviation. (WITTGENSTEIN, 2005, pp. 446, 451)

So, even though for him, say, " $1 \div 3=0 . \dot{3}$ " is perfectly all right, it is a very different type of statement from " $1 \div 2=0.5$ ". But what would exactly be this difference? How in his opinion should we construe the demarcation between these two identities? Wittgenstein's answer to this question is once again surprising. As an initial bold approximation, we could say that he basically claims that " $1 \div 2=0.5$ " is a singular statement whether " $1 \div 3=0 . \dot{3}$ " is a general one! At (2005, pg. 472), for example, we find him comparing many alternative notations for a recurring identity such as “ $1 \div 3=0 . \dot{3}$ " to general statements such as addition's associative law! A little before that he writes:

On the other hand the generality of this rule $[a+(b+c)=(a+$ $b)+c]$ is none other than that of the periodic division $1 / 3=0.3$. That means that nothing in the rule is left open or is in need of completion or the like. (WITTGENSTEIN, 2005, p. 469)

Even thought extravagant, Wittgenstein's line of reasoning here is not very difficult to follow. One of the alternative notations he introduces, while discussing recurrence is:

$$
\frac{1}{1 / 3}=0,3, \quad 1 / 3=0,33, \quad 1 / 3=0,333
$$


(2005, pg. 471)

But these are "partial" results. How could we express, employing Wittgenstein's new notation, what was meant in a "non-partial" statement such as " $1 \div 3=0 . \dot{3}$ " or " $1 \div 7=0.14285 \dot{7}$ "? In the latter case, the left side of our equation would of course simply be

\section{$\mathbf{n}$}

But what about the new right side of (2)? What should we write down?

$$
\frac{\mathbf{n}}{1 / 7}=? ? ?
$$

According to Wittgenstein ${ }^{13}$, our difficulty is a consequence of an oversight. We have missed an operation hidden on the right side of a statement such as (2). The "hidden operation" the philosopher has in mind here would be of course the operation of repetition. In the case of (2) we would have something like:

$$
\left[\lambda \mathrm{n} \cdot \operatorname{Rep}[" 142857 "]_{(\mathrm{n})}\right]
$$

the operation of "repeating the string of digits '142857' n times".

If we use now the symbol " $\neg$ " for "concatenation", we could finally obtain the desired general term which should occupy the right side of (2):

$$
0 \frown \cdot \operatorname{Rep}[" 142857 "]_{(\mathrm{n})}
$$

We could finally complete our rewriting of (2) as:

$$
\operatorname{Div}[1,7]_{(n)}=0 \cap \cdot \cap \operatorname{Rep}[" 142857 "]_{(\mathrm{n}-1)}
$$


Just as Wittgenstein said, in (2') we now surely have a very different statement from a singular enunciation such as " $1 \div 2=0.5$ ”. And just as he said, we can now clearly see the use of variables, just like as in the statement " $a+(b+c)=(a+b)+c$ ". They are both general statements.

From a traditional perspective, it would seem that we would only have to make one final logical gadgetry explicit, the universal quantifier. The variable " $n$ " is of course free in (2'). if we link it, we would get:

$$
\forall n\left(\operatorname{Div}[1,7]_{(n)}=0 \cap \cdot \cap \operatorname{Rep}[" 142857 "]_{(\mathrm{n}-1)}\right)
$$

Would that be it? Would (3) be a completely acceptable version of the ordinary " $\mathbf{1} \div \mathbf{7}=\mathbf{0 . 1 4 2} \ldots$.., even for finicky Wittgenstein? Was that all he had to say about (the rather plain) recurring decimals?

As anyone that is familiar with Wittgenstein's philosophy of mathematics would have guessed, the philosopher would still not be satisfied. Should we take the universal quantifier in (3) classically or, say, intuitionistically? Should we understand (3) as:

$$
\forall_{\text {classic }} n\left(\operatorname{Div}[1,7]_{(n)}=0 \cap \cdot \cap \operatorname{Rep}[" 142857 "]_{(\mathrm{n} / 6-1)}\right)
$$

or as

(3') $\forall_{\text {intuitionistic }}\left(\operatorname{Div}[1,7]_{(n)}=0 \cap . \cap \operatorname{Rep}[" 142857 "]_{(\mathrm{n} / 6-1)}\right)$ ?

These differences do matter, of course. If we accept the classic calculus and it's law of interdefinability of the existential, (3') would turn out to be equivalent to:

$$
\neg \exists_{\text {classic }} n\left(\operatorname{Div}[1,7]_{(n)} \neq 0 \cap . \cap \operatorname{Rep}[" 142857 "]_{(\mathrm{n} / 6-1)}\right)
$$

Not so, of course, if we understand intuitionistically the quantifier. How should we understand the generality involved here? Are these the only two options available? Would there be a third alternative to construe that generality? Following Wittgenstein lead, Dummett 
has always emphasized the idea that those logical options run very deep: they involve very basic questions regarding the very semantics of mathematical statements.

The answer to the question how it is possible to call a basic logical law in doubt is that, underlying the disagreement about logic there is a yet more fundamental disagreement about the correct model of meaning, that is, about what we should regard as constituting an understanding of the statement. (DUMMETT, 1991, p. 17)

Decisions on the rules of logic concerning mathematical statements should be derived from much more general decisions about their semantical interpretation. In other words, we are back to the problem of how to interpret identities and, more generally, how to interpret mathematical statements. Questions about what do they really assert, what should we take as being their content, their connection to "reality", etc. We are thrown right into deep philosophical water; there is no escaping from that.

\section{III - Mathematical Facts}

As we've said before, this paper's main objective is to present Wittgenstein treatment of mathematical identities as back and forth correction. But before we finally do that, though, we will have to quickly review some central elements of the classical and the intuitionistic philosophical construal of mathematical statements in general. These will be important because, by way of contrast, we hope it will end up shedding light on Wittgenstein's proposals.

We will start from a very general interpretational principle about mathematical statements over which the classicists and the intuitionists are in agreement. For both these approaches mathematical statements are true. And they both understand this "being true" as some sort of correspondence: a statement is true because there is something in reality that makes it true. As we will see, classicists and even intuitionists accept the idea of "mathematical facts" habiting some "abstract mathematical reality". It is the (existence) of these facts that 
turn our mathematical propositions into true mathematical statements.

\section{A classical handling of recurring decimal's identities}

The idea that truth of mathematical statements is somehow a consequence of the existence of "mathematical facts" (in some "platonic realm") is usually taken as the distinctive trait of the classical, platonistic approach. This is not a good characterization of the classical position though. As we already anticipated, it would assimilate contemporary intuitionism into the classical camp. This is particularly clear if we take into account the recent proposals, made by Dummett and Prawitz, for distinguishing "warrant assertability" from "truth". But let's not anticipate too much and begin step by step with the classical approach.

Let us consider once more the algebraic version for a recurring decimal's equation we attributed to Wittgenstein, with its two operations, division and repetition:

$$
\operatorname{Div}[1,7]_{(n)}=0 \cap \cdot \cap \operatorname{Rep}[" 142857 "]_{(\mathrm{n}-1)}
$$

In it we have two "unary operations": the operation of "dividing $1 \div 7$ to the $n^{\text {th }}$ decimal place", $\left[\lambda n\right.$. Div $\left.[1,7]_{(n)}\right]$, and the operation of 'repeating the digits '142857' $m$ times", $\left[\lambda \mathrm{n} . \operatorname{Rep}[" 142857 "]_{(\mathrm{m})}\right]$. The key mathematical content of (2") would depend on the fact that, for all decimal places, these two operations coincide.

For a classicist, both these operations should be understood as functions, i.e., as (infinite) sets of ordered pairs (of natural numbers). So, according to classical set theory, even if we accept Wittgenstein's proposal (2'), we would still understand it classically as two different names denoting one and the same mathematical object. According to this approach, this "key mathematical fact" behind (2") would be the fact that both singular expressions

and

$$
\text { “( } \left.(n, m), \in \mathbb{N}: m=\operatorname{Div}[1,7]_{(n)}\right\} "
$$


Wittgenstein on Mathematical Identities

$$
\text { “( } \left.(n, n), n \in \mathbb{N}: m=\operatorname{Rep}[" 142857 "]_{(n)}\right\} "
$$

denote one and the same set, the set:

$$
\{(1,1),(2,4),(3,2),(4,8),(5,5),(6,7), \ldots\}
$$

Wittgenstein's reading of a recurring decimal's identity, with its two operations, is not the usual one, of course. One doesn't normally understand identities involving recurring decimals as general statements (with variables), but as singular statements involving an infinite object:

$$
1 \div 7=0.142 \ldots
$$

Thus, in a more ordinary reading of these identities, recurrence would not even be mentioned, we would only have an operation on the right hand side of the equation and an infinitary object on the left, the "result".

Thus, differently from Wittgenstein, recurrence would not be taken as part of the very semantical characterization of " 0,142 ...", but as a property of some divisions. If we understand the operation $\left[\lambda n \cdot \operatorname{Div}[1,7]_{(n)}\right]$ classically, as set of ordered pairs:

$$
1 \div 7=\left\{(\boldsymbol{n}, \boldsymbol{m}), \in \mathbb{N}: \boldsymbol{m}=\operatorname{Div}[1,7]_{(n)}\right\}
$$

we could then take "repetition" as the property of that set. More precisely, if we understand recurrence as

$$
[\lambda f . \exists c \forall n(d=f(n) \rightarrow d=f(n+c))]
$$

we would take that assertion as:

$$
\left(4^{\prime}\right) \quad|\lambda f . \forall n(d=f(n) \rightarrow d=f(n+6)) \quad|(1 \div 7)
$$

Her we would be talking about an (abstract) object, the "operation $1 \div 7$ ", and would be asserting of that object that it really obeys a 6 cycle. This would be the "mathematical fact" involved. It is because 
the infinite object " $\mathbf{1} \div \mathbf{7}$ " really has the property of recurrence that (4') happens to be a true mathematical statement.

\section{Intuitionistic mathematical facts}

Contrary to a rather common misconception, the adherence to the correspondence theory of mathematical truth, to the idea of mathematical facts, is not characteristic only of the classical approach. From the very beginning in 1959, in his famous article Truth, Dummett has emphasized a similar intuition:

...the correspondence theory expresses one important feature of the concept of truth which is not expressed by the law "it is true that $p$ if and only if $p " \ldots$ : that a statement is true only if there is something in the world in virtue of which it is true. (DUMMETT, 1978, p. 14) apud (MARTIN-LÖF, 1995)

Mathematical statements are descriptive. They record (when true) mathematical facts, aspects of a purely mathematical reality. And of course it is this fundamental representational property that distinguishes true mathematical statements from false ones. Dummett calls this philosophical proposal, the idea of correspondence, principle "Principle C".

Several years later, in another famous article from 1976, What is a Theory of Meaning II?, Dummett better qualifies his adherence to correspondence. He concedes that, taken in isolation, Principle $\mathrm{C}$ is rather "empty" and adds that its main role is to "settle on the appropriate notion of truth for various types of statements":

In general, we can learn something by applying the principle $\mathrm{C}$ to a specific type of statement only when we have already decided something about the sort of thing in virtue of which a statement of that type can be true; (DUMMETT, 1993, p. 53)

So, in the case of mathematics, it becomes natural to ask what type of "facts" should we take to be behind the truth of mathematical statements. What kind of entity should we elect as the truth-makers of mathematical propositions? For a long while, the official intui- 
tionistic answer to this question was the very well known and direct:

Intuitionistically, truth of a proposition is analyzed as existence of a proof; a proposition is true if there exists a proof of it. (MARTINLÖF, 1991, p. 141)

Very recently though, in the late nineteennities, there was a dramatic shift in the way the leading intuitionists answered this question with two different proposals, made by Dummett (DUMMETT, 1998) and by Prawitz (PRAWITZ, 1998), for a distinction between the notions of "warrented assertion" (i.e., possession of a proof) and "mathematical truth". For both Prawitz and Dummett, the "mathematical fact" that turns intuitionistic statements into true mathematical propositions should not be taken to be the simple existence of a proof anymore, but "something else". They agreed that the existence of the proof would only assure us that this fact exists, but should not be understood as coinciding with it (PRAWITZ, 1998, p. 46). Still, they diverged on what this "something else" should be.

The recent shift on what the intuitionists regard as the truth maker of propositions should not come as a surprise. It was already concealed in the simplicity of the previous formula: "truth is the existence of a proof". All we would have to do is to ask the intuitionist about the concept of existence being employed in that formula. Are we talking about "concrete existence", "concrete possession of a proof", or merely its "existence in principle"? As it is well known, if we pressed on the point, the initial simplicity of the formula would give away to much finer distinctions. The intuitionists work with two different notions of proof, canonical and non-canonical proofs ${ }^{14}$. And it turns out that the role played by notion of "existence" regarding these two kinds of proof is also different.

The notion of existence pertaining to a canonical proof is the hardcore notion of "concrete empirical existence". But in the case of a non-canonical proof, the situation is different. A non-canonical proof

14 Dummett also calls them "proofs" and "demonstrations" (DUMMETT, 1991, p. 177). 
expresses only existence "in principle". As we already anticipated above, a proof like that enunciates "the possibility of obtaining a canonical proof" from it. So a non canonical proof is really only a method that, if it were applied, could generate the desired canonical proof (PRAWITZ, 1977, pp. 22, 26; MARTIN-LÖF, 1987, p. 413). In other words, it asserts that that possibility really exists, guaranteed by the (concrete) existence of an intensional object, the method.

The central notion of "proof" is thus clearly that of a canonical proof. ${ }^{15}$ It is the existence of those proofs as syntactical events that could be identified with "mathematical truths". But Intuitionism does not restrict itself to that notion of proof

....It is not true, even Intuitionistically that the condition of asserting a sentence is that we know a proof of it in this sense [the canonical sense]. (PRAWITZ, 1977, p. 21)

To be able to rise above the recording of trivial mathematical identities, Intuitionism is force to include also a second notion of proof, that of a non-canonical demonstration. So, our question now is: what would be the truth-maker for this second type of proof, non-canonical proofs?

There are two possible answers here. We could chose the method, which indirectly ensures the possibility in principle of obtaining the desired canonical object. Or more directly, we could elect the (existence of) the very in principle possibility. Dummett recommends the method as truth-maker of mathematical propositions. (DUMMETT, 1998, p. 123) ${ }^{16}$ Prawitz, on the other hand, insists that that notion of "method" would still be temporal: it is restricted to the methods contemporarily at our disposal. So he proposes to go further and accept a stronger, atemporal notion, of "potential existence of a proof" (and of a method). (PRAWITZ, 1998, p. 48). Future

15 In the case of natural numbers, for example, the canonical notation for them has some very important properties: "sSSSSS0" both denotes the number 6 but also concretely instantiates six successors, "SSSSSS".

16 It is important to notice that this notion of method should not be identified with the classical notion of computability on pains of an infinite regress (PRAWITZ, 1998). It has to be taken as primitive. 
(presently unknown) methods and canonical proofs would have a "potential existence", even today! Either way we have abstract realm populated by "intensional objects", "methods", in the case of Dummett, or populated by "potentialities", in the case of Prawitz.

We won't go into to the problems these proposals may have. Even the more sober one, advocated by Dummett, seems strange at times. For example, we do have a method for calculating Pi's decimal places. But we haven't calculated them all. What should an intuitionist say about these uncalculated decimal places (even if he sides with Dummett)? We would have to say that they exist "in some sense", for their existence is guaranteed by that method. But we don't really have them, because we haven't calculated that far (and never will, for some of these decimal places). So, what should we answer here? What about the decimal places not only as yet uncalculated, but so enormous that it would take, say, the number of seconds since the big band to calculate? Should we still insist that they exist because they "could be reached"? What kind of "capability" would that be? Here we seem to be flirting again with the dangerous concept of an "impossible possibility".

Let us see now Dummett's handling of this problem. We do have a method for calculating Pi, so his answer could not be really much different from:

It seems that we ought to interpose between the platonist and the constructivist picture [a reference to Wittgenstein] an intermediate picture, say, of objects springing into being in response to our probing. We do not make the objects but must accept them as we find them (this corresponds to the proof imposing itself on us); but they were not already there for our statements to be true of false of before we carried out the investigations which brought them into being. (DUMMETT, 1978, p. 185)

But shouldn't we still ask: what crucial difference could there be between saying (with the platonist) that these objects do exist, and Dummett's insistence on the notion of objects "springing into being in response to probing"? Wouldn't that be just a play of words or should we take his proposal more seriously? But if we do, should we also 
accept, say, some kind of "berkelean cake" that would "spring into being" every time we open our refrigerator door?

\section{“Two facts” idea}

In the last section we've seen that both the classical and the intuitionist accept a notion of "mathematical facts". By accepting this notion, it becomes natural for both cases do understand the idea of "applied mathematics" as instantiation. An application of mathematics would be an instantiation of an abstract mathematical structure (form) onto, say, a physical one. The details of how this instantiation would take place are different though for classicists and intuitionists. The very truth makers involved are distinct.

Let us take first the better known classical approach. In Analysis, for example, we have the purely abstract concept of real numbers. And there are also many mathematical facts about them. We can then geometrically apply this theory by using the famous picture of the real numbers as points on a line. Through this picture, numbers become names of positions along a geometrical line. And we can further take this line as, say, a concrete dimension of a physical extension. Our numbers become then names of concrete positions in space. And, of course, mathematical facts about these numbers become physical facts about this (concrete) space.

How would an intuitionist view the idea of applied mathematics? The key point here is the idea that intuitionistic mathematics is made, not of propositions, but of judgments. And judgments are acts. (MARTIN-LÖF, 1987, p. 417) This is why it is so natural for an intuitionist to view programs executed by computers as the very embodiment of mathematics (MARTIN-LÖF, 1979, pp. 5-6). Still, even in the case of computers, we should differentiate the abstract program a computer is supposed to be executing from the concrete machine in front of us. But then, when would we say that the machine is really executing a particular (abstract) program? Well, a program is a specification of how that equipment is supposed to behave, if it is to instantiate that algorithm. In other words, we say that the machine is really following that program when the space of possible concrete 
behaviors of the machine exactly reproduces the abstract space of behaviors prescribed by it.

Once again, we have the idea of an application as an instantiation. The abstract program is instantiated onto the concrete machine. And, just as before, we can distinguish two kinds of facts in this application. We have the "mathematical fact", that that method produces that result. And we have the "physical fact" that that concrete equipment in front of us is (really) following that specification, that the mathematical facts prescribed by the program are really being instantiated by the behavior of that machine.

Wittgenstein was always critical of the "two facts idea". In a lecture in 1939 he directly says:

It is not the case that there are two facts - the physical fact that if one counts the squares [of a rectangle 36 squares long and 21 squares wide] one gets 756 and the mathematical fact that 21 times 36 equals 756 . (WITTGENSTEIN, 1976, p. 39)

Not only Wittgenstein refuses the idea of abstract mathematical objects, such as the numbers and sets as proposed by the classic but, more importantly, he refuses also the intuitionist postulation of "abstract possibilities" as opposed to "real, physical possibilities".

We imagine possible structures and impossible ones, and we distinguish both from real structures. Is seems as though in mathematics we showed what structures are conceivable, imaginable, not real. (WITTGENSTEIN, 1976, pp. 145-6)

He was always critical of the idea of abstract mathematical possibilities as "shadows" of concrete, real possibilities.

We say, for example, that a machine has (possesses) such-and-such possibilities of movement; we speak of the ideally rigid machine which can

17 In the end, Prawitz seems to have the right intuition. The truth maker for intuitionist mathematics appears to be the notion of possibility. It would be odd to say that the possibility exists because the method exists. It seems more natural to say that the method really works because it describes something really possible (an "effective" way of generating that result). 
only move in such-and-such a way.- What is this possibility of movement? It is not the movement, but it does not seem to be the mere physical conditions for moving either ...The possibility of a movement is, rather, a shadow of reality. (WITTGENSTEIN, 1983, p. 86)

The difficulty here is to defend oneself against the thought that possibility is a kind of shadow of reality.

It is one of the most deep-rooted mistakes of philosophy to see possibility as a shadow of reality. (WITTGENSTEIN, 2005, pp. 258,259)

\section{Real, Logical and in principle possibilities}

We have here a key point that neatly differentiates Wittgenstein's and both the classical and the intuitionist's approaches. For both these latter approaches, besides the modal notion of real possibility (understood counterfactually as situations that might happen to occur), we should accept other modal notions. As we've seen, in the case of the intuitionist, we have the notion of "in principle possibility". An "in principle possibility" would be a kind of "second level possibility": a possible existence of a real possibility.

The classicist postulates a third notion of possibility, as distinct from both the intuitionist, in principle, one and from real possibility. It is the notion of a "classical logical-mathematical possibility". The contrast between this notion and the intuitionist's in principle one becomes apparent when we consider mathematical possibilities that not only happen not to describe real possibilities but never could, even "theoretically". As Charles Parsons has pointed out years ago, this is precisely a novelty within Cantorian Set Theory:

It is only when higher infinities of Cantorian set theory are introduced that mathematical objects must violate the conditions of representability in concrete terms. ... If the "physically possible" is what can in some sense be realized in space and time, then structures of sufficiently high cardinality ... are not physically possible. (PARSONS, 1983, p. 191) 
No wonder the intuitionists were so critical of Cantor's mathematical hierarchy of infinitudes. Beyond a certain level ${ }^{18}$, not only are those mathematical structures happen contingently to be noninstantiable (even considering "theoretical" possibilities), but are actually necessarily non-instantiable.

The neat differentiation between Wittgenstein and both the intuitionists and the classicists becomes clear when we consider the fact that the philosopher refuses, not only the stronger classical modality, but even the second level, in principle, notion advocated by the intuitionists.

There is a feeling: "There can't be actuality and possibility in mathematics. Everything is on one level. And in fact, is in a certain sense actual". (WITTGENSTEIN, 2005, p. 495)

As Raymond Bradley has suggested in his series of equations between key semantical, modal and subjective notions, all the way from the Tractatus Wittgenstein's philosophy can be generally characterized by the refusal of any notion of "abstract possibilities" as distinct from "real" ones. For him, the three notions

$$
\text { (Real) possibility }=\text { In principle possibility = Logical possibility }
$$

should always coincide! (BRADLEY, 1992, p. 34)

\section{Non-descriptive Mathematics and Predication}

Besides these modal intuitions, Wittgenstein has two parallel theses regarding the semantics of mathematical statements. The first one is that, contrary to the idea of correspondence suggested by both the classicists and the intuitionists, for him mathematics does not describe any reality. ${ }^{19}$

18 Parsons suggests $2^{2^{\aleph_{0}}}$. (PARSONS, 1983, p. 191)

19 It can be traced of course all the way to the famous Grundgedanke of the Tractatus. (WITTGENSTEIN, 1961, p. 4.032) 
In mathematics everything is algorithm, nothing meaning; even when it seems there's meaning, because we appear to be speaking about mathematical things in words. What we're really doing in that case is simply constructing an algorithm with those words. (Big Typescript. pg. 494) I am trying to say something like this: even if the proved mathematical proposition seems to point to a reality outside itself, still it is only the expression of acceptance of a new measure (of reality). (RFM, 162)

This is a very early insight of Wittgenstein's. It is already clearly present in the famous grund gedanke of the Tractatus. (WITTGENSTEIN, 1961, p. 4.032). Empirical, contingent propositions describe. Necessary statements such as logical laws, mathematics or even philosophy do not describe anything, but prescribe.

For Wittgenstein, the confusion between these two "grammars" is a very common, deeply rooted and extremely pernicious mistake among philosophers and mathematicians. He is always adverting against the idea of approximating empirical and mathematical statements:

The confusions in these matters are entirely attributable to treating mathematics as a kind of natural science.

Nothing is more disastrous to philosophical understanding than the notion of proof and experience as two different - yet still comparable - methods of verification. (WITTGENSTEIN, 2005, pp. 429,419)

Mathematicians, when they begin to philosophize, always make the mistake of overlooking the difference in function between mathematical propositions and non-mathematical propositions.

These discussions have had one point: to show the essential difference between the uses of mathematical propositions and the uses of nonmathematical propositions which seem exactly analogous to them. (WITTGENSTEIN, 1976, p. 111)

He goes as far as denying that the notions of truth and falsity should be applied to mathematical statements:

The terms "sense" and "nonsense", rather than the terms "true" and "false", bring out the relation of mathematical propositions to nonmathematical propositions. (WITTGENSTEIN, 1979, p. 152) 
Not surprisingly, the big differences in semantical function Wittgenstein sees between empirical and mathematical statements determine for him parallel fundamental distinctions in the very grammatical structure of these assertions. In fact, the philosopher denies that predication can be at all present in mathematical statements. One again, the textual evidence is very forceful:

Is $2+2=4$ a proposition about 2 and about 4 ? Compare this proposition with "There are no other men in this room than Jack an John". ...if "There are two men here" is taken to be about 2, then it is misleading to say $2+2=4$ is about 2 ; for it is "about" it in a different sense. (Lectures 1934-35, pg. 155)

...a mathematical proposition is not about its constituents in the sense in which "The sofa is in this room" is about the sofa. . (LFM, Lectures 1939 XXVI, pg. 254)

...mathematical propositions do not treat of numbers. Whereas a proposition like "There are three windows in this room" does treat of the number 3. (LFM, Lectures 1939 XXVI, pg. 250)

Suppose I say "Prince has blue trousers"; that is a proposition about trousers. (....)

What about "two"? "2 $+2=4$ " - but this isn't about 2 ; it is grammatical.

Turing: Isn't it merely a question of how one extends the use of the word "about"?

Wittgenstein: That is a most important mistake. - Of course you can say mathematical propositions are about numbers. But if you do, you are almost sure to be in a muddle. (LFM, Lectures 1939 XXVI, pg. 251)

\section{IV - Back and Forth Correction}

\section{The Metalinguistic Component}

We have dedicated the entire part III of our article to review some very general traits on how classicists and intuitionists construe the semantics of mathematical statements and their application, say, to physics. We've seen that both these schools propose nothing less than a bifurcation of the notion of reality in two. Aside from the concrete, empirical reality, we would also have an abstract, logical- 
mathematical one. Once this bifurcation is effected, we can then explain mathematical truth as the existence of the appropriate facts within the abstract realm. On the other hand, application of mathematics is construed as instantiation. There is a isomorphism between some aspect of empirical reality and some mathematical structure. Through this isomorphism, names of mathematical objects (numerals, for example) become also names of empirical entities (say, extensions). And thus mathematical facts concerning these objects are nicely transferred to that part of empirical reality.

As we've seen, Wittgenstein was very critical of the "two facts" idea. He rejected altogether any notion of a mathematical abstract reality, even if this reality was to be populated only by abstract potentialities. For him, mathematical statements neither talk about, nor answer to any abstract realm, no matter how this realm might happen to be construed. In fact, he goes as far as denying the very applicability of predication (and of the notion of "truth") to mathematical statements! Mathematics simply does not talk about anything.

If mathematical statements do not talk about anything, how is their semantics to be understood? If, say, " $2+3=5$ " is not a statement about numbers, nor any other abstract objects, not even about abstract possibilities (of obtaining some canonical form), what is it about then?! What semantical role would Wittgenstein accepts for mathematics? What do mathematical statements assert? After all, in order to have any meaning, it appears that they are bound to assert something... about something else. This is where the notion of "back and forth" correction comes in. There are two elements involved in this notion. The first, and most important one, is the metalinguistic element. The second one is the normative and deontic component. Let us begin with the metalinguistic component.

As in the case of so many of Wittgenstein's key ideas, this one is also derived from Frege. In his Grundlagen der Arithmetik, we find this very striking passage by the German philosopher:

It is true that at first sight the proposition "All whales are mammals" seems to be not about concepts but about animals; but if we ask which animal then are we speaking of, we are unable to point any one in particular. Even supposing a whale is before us, our proposition still does not state anything about it. We cannot infer form it that the animal 
before us is a mammal without the additional premise that it is a whale, as to which our proposition says nothing. (FREGE, 1978, p. 60)

The image of an immense whale laying directly before us is extravagant. And when we say "All whales are animals" we do seem to be talking about whales (saying that they are mammals). This is what traditional logic (and ordinary grammars) has always taught us, ever since Aristotle. And there is that enormous animal in front of us. But Frege refuses the idea that the rule "All whales are animals" does in any way talk about those concrete creatures. As we know, his strange proposal was that the statement assertes something about a complex concept instead, the concept " $[\lambda x$. Whale $(x) \rightarrow$ Mammal $(x)$ ]", saying about that concept that it is universally valid. This is Frege's famous idea of "second order predication": general statements do not talk directly about empirical reality, but only establish connections between concepts.

We know that for Frege, even though statements like "All whales are animals" did not talk about empirical reality, they did talk about an "alternative abstract reality". In fact, Frege is famous for having gone as far as fully accepting the idea of a "third realm" (FREGE, 1977a, p. 17), an independent abstract reality in which these conceptual connections actually "were the case". As we've seen, Wittgenstein could not accept this idea of a bifurcation of reality into realms. But there was something in Frege's proposal that interested him. This was the idea of a "second order connection" of the rules vis-à-vis empirical reality. Mathematical statements did not talk directly about reality, but only establish metalinguistic rules (Frege's "connections") for meaningful employment of these words (Frege's "concepts") in empirical contexts:

One might also put it crudely by saying that mathematical propositions containing a certain symbol are rules for the use of that symbol, and that these symbols can then be used in non-mathematical statements. LFM, lecture III, pg. 33

To sum up, I have tried to show that the connection between a mathematical proposition and its application is roughly that between a rule of expression and the expression itself in use. (WITTGENSTEIN, 1976, pp. 33, 47)

The important point to be stressed here is that on Wittgenstein's hands Frege's second order predication becomes fully metalinguistic. 
To the despair of his famous interlocutor, he is always introducing the operator "call" in all his formulations of mathematical statements

"This is what we do when we perform the process which we call "multiplication". 144 is what we call "the right result".

Supposing we do a multiplication: the use of this is that we aren't willing to recognize a rule of multiplication unless it can be got in a particular way. For instance, we do not accept the rule that $1500 \times$ $169=18$. We should not call that a multiplication. (WITTGENSTEIN, 1976, pp. 97, 106) ${ }^{20}$

Differently from the philosopher, his interlocutor wants to leave mere metalinguistic description behind and go back to the idea of truth, good old answerability to a mathematical reality.

"Is that supposed to mean that it is equally correct whichever way a person counts, and that anybody can count as he pleases?" - We should presumably not call it "counting" if everyone said the numbers one after the other anyhow.

"Then according to you everybody could continue the series as he likes; and so infer anyhow!" In that case we shan't call it "continuing the series" and also presumably not "inference". (WITTGENSTEIN, 1983, pp. 37, 80)

Wittgenstein's answers - “..we should presumably not call it "counting....", “... in that case we shan't call it 'continuing the series' and also presumably not 'inference"” - are precisely meant to reintroduce the dreaded metalinguistic point of view, blocking the idea of any "answerability to an abstract reality", the recovery of a "descriptive content".

\section{The Normative Component and Disqualifying Criteria}

The second element in Wittgenstein's idea of back and forth correction is now immediate. If there is to be no remaining "descriptive content" 
in Wittgenstein's notion of "rule", then we are left with a purely normative connection. As usual, Wittgenstein is ready to follow this idea wherever it might lead. He goes as far as proposing:

Suppose we look at mathematical propositions as commandments, and even utter them as such? "Let $25^{2}$ be $625 . "$

Can we imagine all mathematical propositions expressed in the imperative? For example: "Let $10 \times 10$ be 100". (WITTGENSTEIN, 1983, pp. 271, 276)

Mathematics doesn't describe anything. It does not talk about ideal, abstract entities. It is purely prescriptive. It prescribes criteria for the correct usage of certain terms such as "line", "angle", in ordinary empirical situations, what Wittgenstein calls "grammatical rules":

Geometry isn't the science (natural science) of geometric planes, lines and points, as opposed, say, to some other science whose subject matter is gross physical lines, strips, surfaces, etc. and that states their properties. The connection between geometry and propositions of practical life, which are about strips, color boundaries, edges and corners, etc. doesn't consist in geometry's speaking of things similar to what these propositions speak of, although geometry speaks about ideal edges and corners, etc.; rather, it consists in the connection between these propositions and their grammar. Applied geometry is the grammar of statements about spatial objects. (WITTGENSTEIN, 2005, p. 391)

The best way to regard these "rules" is to take them, not as positive determinations, but as negative ones, as constraints on empirical statements. In other words, it is best to regard them as establishing criteria for disqualification of empirical claims. Let us take a simple example. Suppose we consider the usual geometric procedure for bisecting an angle with a compass. Does it make sense to say that an "ideally executed" instance of that procedure would have the "property" of generating two equal angles (but rough empirical operations would just "approximate" that abstract ideal)? No, not for Wittgenstein. According to him, the "mathematical content" of that technique is a connection between certain procedures and the concept "equal 
angles". This connection is then used to judge (and maybe discard) empirical allegations.

If I regard construction as my criterion, I can by no means check the division of angles by measurement. The case is much rather this: if measuring yields a difference, I shall say, the compass is faulty, that was not a straight line, etc. For construction is now my standard according to which I judge the quality of a measurement. (WAISMANN, 1979 , p. 205)

Other geometrical examples of rules from his intermediary period are:

The proposition "corresponding angles are equal" means that if they aren't found to be equal when measured I will declare the measurement incorrect; and the "sum of the angles of a triangle is 180 degrees" means that if it doesn't turn out to be 180 degrees when they are measured I will assume there has been a mistake in the measurement. (WITTGENSTEIN, 2005, p. 391)

\section{Back to recurring decimal's identities}

We now have all the elements at our disposal to finally complete our discussion of Wittgenstein's favorite example of a mathematical identity, the ones involving recurring decimals. Let us then go back to where we left our discussion of those identities, to the new version proposed by the philosopher in which the two operations of division and repetition are clearly brought forward.

$$
\operatorname{Div}[1,7]_{(n)}=0 \cap \cdot \cap \operatorname{Rep}[" 142857 "]_{(\mathrm{n}-1)}
$$

So, how should we then interpret this general equation according to Wittgenstein? Not so with the help with the usual quantifiers, being them intuitionistic or classic, but as back and forth correction. In other words, we are going to employ both the metalinguistic component introduced by the expression "Whatever one calls...', and the normative component introduced by the expression "one must..". The complete formulation would be something like this: 
Whatever one calls "the result of the operation dividing to the $n^{\text {th }}$ decimal place"

one must also call "the result of the operation of writing " 0 ," and of repeating

“142857” through $n-1$ places, and vice versa

Wittgenstein is very explicit about both these components in his later discussions on recurring decimals. Let us start with the normative component. In his Lectures on the Foundations of Mathematics in 1939 he writes:

Here I am adopting a new criterion for seeing whether I divide this properly - and that is what is marked by the word "must". (WITTGENSTEIN, 1976, p. 129)

For Wittgenstein, the mathematical advance involved in the notion of "recurring decimals" is best viewed as mutation of our language. We find ourselves adopting new criteria for old words.

We actually have in $\dot{3}$ a new symbol. $\underline{1}_{1}: 3$ is a new operation and has the result in a different sense than $1 / 3$. (ATL, $P 211$ )

Before our "language mutation" we could actually detect the repetition of some digits. But we lacked altogether the concept of "recursion".

If we follow the rules as we do follow them, being prepared as we are, then this is what will always happen [the recursion]. (WITTGENSTEIN, 1976, p. 129)

After the linguistic mutation, we have a new normative criterion, expressed by a "timeless must", a rule:

Then later he takes recurrence as the criterion: "it must happen”.(Timeless “must') (WITTGENSTEIN, 1976, p. 129)

Wittgenstein is not always completely careful in his usage of the two words, "repetition" and "recurrence". In the second quote 
above about the linguistic situation before the language mutation, he uses "recursion" to refer to the repetition of digits one could detect even before the adoption of the new concept of recurring decimals. ${ }^{21}$ But even with these minor terminological oscillations, the distinction between recursion and repetition is clearly emphasized:

Periodicity does not mean the same as several repetitions of the same number or numbers, but makes a new calculus. (WITTGENSTEIN, 1979, p. 187)

Similarly with "[ I ] believe it will recur". (...) You might believe in two totally different things. The phrase is misleading: "will recur" as normally used is a mathematical phrase. It is not a temporal expression; it doesn't mean "will recur [repeat] with most people" or "will recur [repeat] in half an hour" or anything like that. (WITTGENSTEIN, 1976, p. 124)

\section{The connection between "repeating" and "dividing" and new kinds of errors}

Let us now focus our attention to the second component in the idea of back and forth correction, the metalinguistic connection between the notion of "repeating" and that of "dividing". Here the importance of Wittgenstein insistence on a "hidden operation", the "geometrical" operation of "repeating a pattern", becomes clear:

The question of recurrence is then a strictly geometrical question: the man will be persuaded that if the repeats this pattern here, there must be the same numeral repeated (A new criterion that he has done so-andso) (WITTGENSTEIN, 1976, p. 130)

The new rule connects the two concepts, using one as correcting criteria for the other. Wittgenstein's proposal is best visualized by an imaginary experimental psychology like procedure involving two subjects, $\mathrm{A}$ and $\mathrm{B}$. We ask $\mathrm{A}$ to perform the division $1 \div 7$, let us say, all the way up to 100 decimal places (we can imagine him

21 This may have to of course do with the origin of the text: a transcription of his lectures. 
using a Turing machine tape for that). And we ask B to execute the operation of writing " 0 " and then repeating the digits "142857" through 99 extra places (he can also do that in a squared tape). The idea is that we can use the comparison of the two tapes as a way of checking if the two orders were correctly executed. Any mismatch between them would be an indication of a misapplication of (at least) one of the procedures.

It is important to notice that the correcting routine can go either way. Normally, if we've noticed a mismatch between the tapes, it would be reasonable to expect a mistake in A's execution of the command (the one that was carrying out the division). This is due to the fact that his operation is much more error prone than the other. But, if the two tapes happen to be off by, say, only one place and present otherwise identical patterns, such as in:

\begin{tabular}{l|l|l|l|l|l|l|l|l|l|l|}
\hline $\boldsymbol{\cdots}$ & $\mathbf{1}$ & $\mathbf{4}$ & $\mathbf{2}$ & $\mathbf{8}$ & $\mathbf{5}$ & $\mathbf{7}$ & $\mathbf{1}$ & $\mathbf{4}$ & $\mathbf{2}$ & $\mathbf{8}$ \\
& 91 & 92 & 93 & 94 & 95 & 96 & 97 & 98 & 99 & 100 \\
\hline
\end{tabular}

it would be reasonable to expect a mistake by B (the one carrying out the repetition). This would be because in the case of the division, of course, a mistake in one quotient digit would clearly disrupt the entire recurring pattern (and we could even end up halting at the end of the process).

Wittgenstein is again very conscious of symmetrical character metalinguistic dependence asserted. In his Remarks on the Foundations of Mathematics he writes:

Suppose that when we worked out a division and it did not lead to the same result as the copying of its period. That might arise e.g. from our altering our tables, without our being aware of it. (Though it 
might also arise from our copying in a different way)

(WITTGENSTEIN, 1983, p. 263)

It is important to stress this point because, as we anticipated before, it indicates a very significant connection between him and Frege. Even though Wittgenstein is very far from the triangular construal of mathematical identities and its idea of an "abstract object" (being denoted by both sides of the equation), his reading of " $1 \div 7=$ $0 . \dot{14285} \overline{7}^{\prime}$ is completely flat. The correction he proposes can go either way (although it might go one way more often than the other). The paring of the two concepts puts them on the same level, each one as furnishing correcting criteria of the other.

There is a second, very important point to be emphasized here. Each new rule introduces new kinds of mistakes. Before the rule connecting the two operations, one could err the execution of the division $1 \div 7$, say, because one of the partial quotients was wrong. After the introduction of the new rule, one could claim that the operation was not actually performed, not because one had any local mistake one could spot, but merely because, say, a digit "6" had showed up within that expansion. It is an essential element in Wittgenstein's view of mathematics that each new proof, each new conceptual connection, establishes new possibilities of error, new ways of disqualifying allegations that, say, such as such operations were performed.

\section{Each side operation taken in isolation}

In the last section we have introduced an imaginary situation in which two subjects, $\mathrm{A}$ and $\mathrm{B}$, executed two operations, repeating and dividing, which were connected by a prescription, a rule. It is important to emphasize the purely normative, metalinguistic connection between the rule and those empirical operations. For Wittgenstein, a mathematical rule is completely impersonal and atemporal. ${ }^{22}$ It does not talk about any specific empirical operations 12-3)

22 Once again, Wittgenstein is reminiscent of Frege. Cf. (FREGE, 1964, pp. 
performed by particular computing agents ("that computer on my desk top") on any specific occasions ("this morning"). In fact, as we've seen before, rules do not talk about anything. They merely lay criteria that are used to disqualify empirical claims, allegations that, say, such and such an operation was actually performed by some agent in some determinate situation.

Wittgenstein is quite forceful about both the atemporal and the impersonal character of rules. He writes:

Questions of fact always involve time; mathematical facts or propositions do not. (WITTGENSTEIN, 1979, p. 184)

"The 100 apples in this box consist of 50 and 50" - here the nontemporal character of "consist" is important. For it doesn't mean that now, or just for a time, they consist of 50 and 50. (WITTGENSTEIN, 1983, p. 74)

In mathematics we have propositions which contain the same symbols as, for example, "Write down the integral of...", etc., with the difference that when we have a mathematical proposition time doesn't enter into it and in the other it does. (WITTGENSTEIN, 1976, p. 34)

Regarding the impersonal trait, contrary to any communitarist reading of rules, Wittgenstein writes:

"The rule, applied to these numbers, yields those" might mean: the expression of the rule, applied to a human being, makes him produce those numbers from these. One feels, quite rightly, that that would not be a mathematical proposition. (WITTGENSTEIN, 1983, p. 228)

"But mathematical truth is independent of whether human beings know it or not!"--Certainly, the propositions "Human beings believe that twice two is four" and "Twice two is four" do not mean the same. The latter is a mathematical proposition; the other, if it makes sense at all, may perhaps mean: human beings have arrived at the mathematical proposition. The two propositions have entirely different uses. (WITTGENSTEIN, 2005a, pp. 192-3)

Even if an agent has executed an operation for the first time, for example, a computer spitting out a new place in Pi's decimal expansion, it's results can be taken atemporally, that is, if this "new rule" is ever used to "judge proceedings": 
In a calculation I surely wanted from the beginning to know what the result was going to be; that was what I was interested in. I am, after all, curious about the result. Not, however, as what I am going to say, but as what I ought to say. (WITTGENSTEIN, 1983, p. 195)

The importance of stressing the impersonal and atemporal character of rules comes out very clearly if we consider the shift that takes place when we focus on one of the two operations paired by the rule considered in isolation from the other. Let us take, for example, the operation $\left[\lambda n\right.$. $\left.\operatorname{Div}[1,7\}_{n}\right]$. If Wittgenstein accepts a notion of a "connecting rule", above and beyond any actual practice of human (and electronic) agents, does he also accepts the notion of an abstract operation as a mathematical entity distinct from any particular empirical implementation? In other words, does he accepts the notion of "function" (and that of an "algorithm") as an abstract specification of a "purely mathematical" procedure?

Once again, Wittgenstein's proposal is extravagant. His answer is a resounding: No! One can have a rule prescribing converse correctibility of pairs of concepts (such as repeating and dividing). And this pairing is laid down both atemporally and impersonally. But that doesn't mean that we can now, say, "detach" the concept of "division" from that rule and talk about an "abstract" version of that operation. We do have the rule

$$
\operatorname{Div}[1,7]_{(n)}=0 \cap \cdot \cap \operatorname{Rep}[" 142857 "]_{(\mathrm{n}-1)}
$$

and this rule prescribes atemporally and impersonally. But for him it does not make sense to talk about an "atemporal" and "impersonal" entity represented by each side of that equation taken in isolation. In other words, it does not make sense to talk about some "abstract operation" of division

$$
\left[\lambda n \cdot \operatorname{Div}(1,7)_{n}\right]
$$

Wittgenstein writes:

We use the expression: "the steps are determined by the formula...". How is it used? - We may perhaps refer to the fact that people are 
brought up by their education (training) so to use the formula $y=x^{2}$, that they all work out the same value for $y$ when they substitute the same number for $x$.

The way the formula is meant determines which steps are to be taken. What is the criterion for the way the formula is meant? Presumably the way we always use it, the way we were taught to use it. (WITTGENSTEIN, 1983, pp. 35, 36) ${ }^{23}$

It is here that the communitarist element in his thinking forcefully comes in. To the despair of the mathematician, Wittgenstein insists introducing "people" and the "way they are trained" ("nowadays") in his discussion of what would normally be taken as a "purely mathematical" operation.

This is not, of course, what his interlocutor has in mind. The mathematician wants to talk about an abstract concept of a "function", not a behavior of concrete, calculating agents. Instead of the purely normative, metalinguistic connection (between "what one calls repeating and what one calls dividing") the mathematician wants to introduce back a descriptive component. Even if we accept Wittgenstein's introduction of a second operation within the recurring decimal's identity, we are still talking about computational procedures, division and repetition. And so, according to the interlocutor, we have two independent algorithms that fix the values of their infinite expansions quite independently of each other (contrary to what the philosopher claims). It so happens that both these algorithms do generate (abstractly) the same mathematical function.

Above and beyond any metalinguistic converse correctibility advocated by Wittgenstein, his interlocutor' retorts that this is precisely the content being asserted by that equation. One has two abstract operations, two algorithms. And the identity merely registers a mathematical fact, the fact that these two algorithms do describe one and the same mathematical function. In other words, the same intentional object, a function, is "in fact" denoted by both sides of that identity statement. This is what is being asserted by that statement and this is what Wittgenstein should accept. Back and forth correctibility is at best a consequence of that prior mathematical fact. 


\section{Wittgenstein's rejection of the notion of function in extension}

The reintroduction of a descriptive component and the classical, triangular construal of the identity, pointing to an "abstract object", is of course precisely what Wittgenstein is advising us to avoid. But let us continue following the interlocutor's suggestions. Consider a computer like description of the algorithm for $\left[\lambda n . \operatorname{Div}(1,7)_{n}\right]$ such as, say:

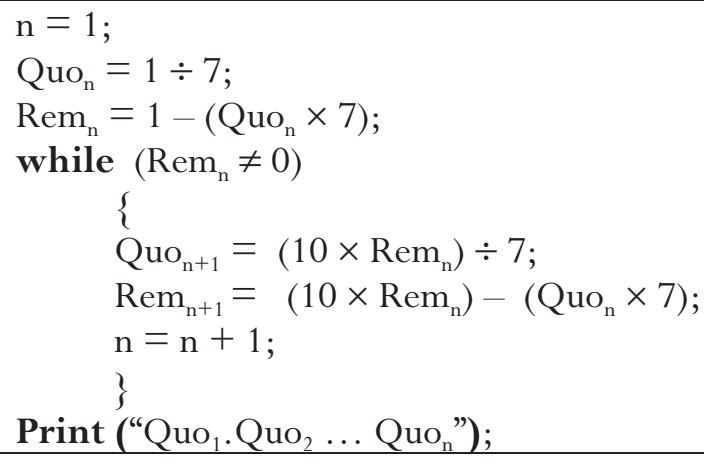

Why shouldn't we say that this description fixes the algorithm "Division of $1 \div 7$ " (quite apart from any connection to any repetition)? After all, if we do "run it" in a computer, the digits that do come out will be " 0,14285714 ...". Why can't we say that this procedure "determines ahead an infinite sequence of values of that abstract operation", that it "establishes" all digits of that (recurring) expansion quite apart from any actual implementation of it by a concrete computer (or human being)? Wittgenstein writes:

We have then a rule for dividing, expressed in algebraic or general terms,-and we have also examples. One feels inclined to say, "But surely the rule points into infinity-flies ahead of you - determines long before you get there what you ought to do." "Determines" - in that it leads you to do so-and-so. But this is a mythical idea of a rule -flying through the whole arithmetical series. (WITTGENSTEIN, 1976, p. 124) 
Here I should first of all like to say: your idea was that that act of meaning the order had in its own way already traversed all those steps: that when you meant it your mind as it were flew ahead and took all the steps before you physically arrived at this or that one. Thus you were inclined to use such expressions as: "The steps are really already taken, even before I take them in writing or orally or in thought." And it seemed as if they were in some unique way predetermined, anticipated--as only the act of meaning can anticipate reality. (WITTGENSTEIN, 1993, p. 64)

The philosopher refuses any idea of an operation "operated by no one in no particular time". Wittgenstein calls this a "mythical idea of a rule". He does accept, say, a rule connecting division and repeating, of course. And he accepts this connection as being completely independent of any empirical operations by concrete calculating agents, it is not tributary to any (empirical) reality. But he thinks it is a fundamental mistake when we move on from a atemporal and impersonal view of rules to an atemporal and impersonal (i.e., "abstract") view of concepts and operations. In short: Wittgenstein rejects nothing less than the very concept of a function in extension!

We won't be able to go into the complexities involved in Wittgenstein's negative to such basic classical concept. We will have to leave that for a future paper entirely dedicated to that. Besides, this would take us to far from our main objective here, the positive presentation of his treatment of mathematical identities. Here we will only be able to quickly sketch the main elements of that argument, as applied to our favorite example, the division $1 \div 7$. As we will see, the key element of Wittgenstein's argument against the notion of function can be found in Kripke's famous Wittgenstein on Rules and Private Language and his idea of a "non-standard metalinguistic interpretation" of normal ordinary functions (KRIPKE, 1972, pp. 16, note 12$)$.

Let us go back to the idea of back and forth correction. When we presented Wittgenstein's proposal, we emphasized the idea that each new rule introduces new possibilities of error, new senses in which one can disqualify empirical claims (regarding some operations, say). As examples, we gave both the employment of division as correcting criteria for repetition (in the case when the two sequence of digits 
are off by one tape's box) and repetition as criteria for division (when we discard a "result" because it contains, say, a "6" as one of the partial quotients). According to the philosopher, all these possibilities of mistake are part of the "language mutation" engendered by the new metalinguistic pairing of the two operations. And that much is essential to his conception of a "language mutation": some utterances that (before) could describe possible proceedings are now discarded off hand. We have new criteria for meaningfulness of such claims. And new possibilities of error.

With this idea in mind, let us now entertain for a while the interlocutor's triangular view of the equation

$$
\operatorname{Div}[1,7]_{(n)}=0 \cap . \cap \operatorname{Rep}[" 142857 "]_{(\mathrm{n}-1)}
$$

As we've seen, for him both sides of that identity denote one and the same "mathematical object", the function in extension

$$
\{(1, \mathbf{1}),(2,4),(3,2),(4, \mathbf{8}),(5, \mathbf{5}),(6,7), \ldots\}
$$

the "very mathematical fact being registered by that identity". So let us accept all that. Let us introduce, with him, a third entity, the "extension" (alongside with the two previous operations). According to our interlocutor, we would now have two "mathematical operations", the two "algorithms", and a "infinitary object", the extension “0,1428571428 ...”.

Let us look to our situation from the point of view of Wittgenstein, now. For him, the introduction of this "infinitary object" would represent the acceptance of new correcting criteria for the two previous operations. This "mysterious object" could function now as a kind of "Paris' standard meter" for the two other operations. We could even introduce a new procedure: the operation of "copying an initial section of that (infinitary) prototype". This would then introduce a third source of criteria for the other two procedures. We would have two new rules, a rule connecting the division and that "extension", and a similar one connecting the repetition and the "infinitary object". And, as the philosopher emphasizes, the acceptance of these "new rules" would represent a language mutation in which it would then make 
sense to talk about new kinds of mistakes, new criteria for the disqualification of claims regarding empirical operations.

Let us take, for example, the operation of division. Before the introduction of the "new object", if we wanted to claim someone was mistaken in his execution of the division $1 \div 7$ we would have to present him, either with a section of his calculus in which his partial operations were flawed, or, using the connection with the cycle "142857", point to him a section of his result that did not followed that pattern. With the new "infinitary object" though, it would suddenly make sense to accuse him of error, not because of any internal mistake in the division, or of an external mistake identified by the pattern "142857", but because his result diverged from the (infinite) sequence of numbers stored within the mysterious infinitary stand-

ard 0,142857142857142857142857142857142857 ...

We would now have three interconnected operations: the division $1 \div 7$, the repetition 142857 and the copying of some initial segment of that infinite standard. But, differently from the other two, this "third operation" involved an "abstract" standard "not accessible in its entirety" by anyone, in no "empirical length of time" (however long that may be). It would be a "guiding criteria" that would always be "partially beyond" the reach of any agent in any given empirical situation.

This is precisely where Kripke's skeptical doubts come in. With the introduction of this "permanently, partially elusive object" we have left our guards wide open to bizarre hypotheses such as those we find in (KRIPKE, 1972, p. 9). If this "Paris functional standard" makes sense, then it suddenly appears possible some kind of a strange "undetected Babel". What if half of the world's population has always employed one "division's prototype" and the other half employed a second prototype, but we haven't discovered the discrepancy because we haven't calculated that far? If each of us has some "function in extension", some "Division prototype" fixing ahead all decimals of our "infinite expansion", how do we know that our "complete standard" is the same as our neighbors'? What if the as yet "unsurveyed continuations" diverge beyond certain section? 
The idea is very similar to skepticism about, say, our neighbor's "internal sensation of green". In both cases we have an unreachable standard. In the case of the private sensation, the standard is unreachable by anyone save the first person. In the case of the "infinite expansion object", the standard is not ("completely") reachable by anyone. Both constructs open ourselves up to strange forms of skepticism. Wittgenstein writes:

The essential thing about private experience is really not that each person possesses his own exemplar, but that nobody knows whether other people also have this or something else. The assumption would thus be possible--though unverifiable--that one section of mankind had one sensation of red and another section another. (WITTGENSTEIN, 2005a, p. 81)

As we have said before, every new criterion introduces new possibilities of mistake. According to Wittgenstein (and Kripke), the price we would have to pay for the introduction of our "mysterious standard", i.e., the notion of function in extension, would be nothing less than the wild endanger of all communicational possibilities. Kripke's lugubrious conclusions heralds precisely this scenario:

Of course, ultimately, if the skeptic is right, the concepts of meaning and intending one function rather than another will make no sense.

....if this is correct, there can of course be no fact about which function I meant. (Rules and Private language, 13)

There can be no such a thing as meaning anything by any word. ... any present intention could be interpret so as to accord with anything we may choose to.

What can be said on behalf of four ordinary attributions of meaningful language to ourselves and to others? Has not the incredible and selfdefeating conclusion, that all language is meaningless, already been drawn? (KRIPKE, 1972, pp. 13, 54, 71) 
The generalization of the idea of back and forth correction

Our rejection of the expression " 0,142 ..." as a singular term lead us to introduce a variable and a further operation of repetition, obtaining the general identity statement

$$
\operatorname{Div}[1,7]_{(n)}=0 \cap . \cap \operatorname{Rep}[" 142857 "]_{(\mathrm{n}-1)}
$$

What about a singular identity statements such as our previous

$$
2+3=5 ?
$$

How would Wittgenstein deal with these statements?

The philosopher's final generalization of the notion of back and forth correction was slow to come to him. A mature, more stable view of the semantics of "rules" is only achieved in his final years, few years after his intermediary period represented by the Big Typescript. ${ }^{24}$ But with the final explicit introduction of what we've called the "metalinguistic component" in his interpretation of identities, Wittgenstein is able to provide an uniform treatment of all these cases.

About the addition " $200+200=400$ " he writes:

The proof is now our model of correctly counting 200 apples and 200 apples together: that is to say, it defines a new concept: "the counting of 200 and 200 objects together". Or, as we could also say: "a new criterion for nothing's been lost or added. (WITTGENSTEIN, 1983, p. 161)

Multiplications such as " $25 \times 25=625$ " and " $16 \times 19=304$ " are equally interpreted as back and forth corrections:

The fact that I have $25 \times 25$ nuts can be verified by my counting 625 nuts, but it can also be discovered in another way which is closer to the form of expression " $25 \times 25$ ". And of course it is in the linking of

24 For a extremely careful treatment of this development, cf. (FRASCOLLA, 1994, p. Chap 2) 
these two ways of determining a number that one point of multiplying lies. (WITTGENSTEIN, 1983, p. 357)

Multiplication could be defined by an empirical criterion. If you have 16 rows of soldiers, 19 in each row, the result by multiplication will be the same as by adding. - One feels inclined to say that if he reaches a different result from such-and-such, then he cannot mean the same by the signs as we ordinarily mean by them. "If ' $X$ ' means the same, then $16 \times 19$ must have this result." (WITTGENSTEIN, 1976, p. 80)

In all these cases we have a pairing of two different operations. "Whatever is taken" as the result of the operation "counting 625 nuts" (a certain pile of nuts) is linked to "whatever is taken" as the result of the operation "counting 25 and 25 and then multiplying". For Wittgenstein, this "pairing" is nothing less than the "point of multiplying"! The metalinguistic component is clearly introduced by the philosopher: "If ' $X$ ' means the same, then $16 \times 19$ must have this result".

Wittgenstein clearly differentiates between empirical propositions (involving agents and intervals of time) and (metalinguistic) rules. These latter do not talk about the world, about physical events, but merely lay criteria for the acceptability of such reports. Let us take the operation of "gathering 2 and 2 apples on a table". If we are talking about an actual event ("in reality"), about that specific "gathering" executed by someone at some particular occasion, then according to Wittgenstein we are doing an "experiment". If this operation is done "as we usually do it", then we could even expect to count 4 apples on the table (if this latter "counting" is done as we usually do it).

Put two apples on a bare table, see that no one comes near them and nothing shakes the table; now put another two apples on the table; now count the apples that are there. You have made an experiment; the result of the counting is probably 4. (WITTGENSTEIN, 1983, p. 51)

This is not what rules such as " $2+2=4$ " and " $4+1=5$ " say. As any other rules, these do not talk about empirical situations, but merely lay norms, criterions for reports (on events involving such operations, as "counting" and “adding”): 
If we put 3 things by 2 things, that may yield various counts of things. But we see as a norm the procedure that 3 things and 2 things make 5 things. See, this is how it looks when they make 5. (WITTGENSTEIN, 1983, p. 310)

It is not supposed to be an empirical proposition that the rule leads from 4 to 5 , the this, the result, must be taken as the criterion for one's having gone by the rule. (WITTGENSTEIN, 1983, p. 319)

The number "5" should not be understood as being defined out of the number "4" (by the abstract "successor function"). We have a flat pairing of two concepts: "counting ' 4 ' and ' 1 ' and gathering” and "counting ' 5 "'. The first concept can function as much as correcting criteria for the second as the second towards the first.

Just as in the case of the recurring decimals, the atemporality and impersonality of the rule applies only to the "complete" statement: " $2+3=5$ ". If we take but one side of that pairing and inquire, say, "what it is to count 5?", the answer would be: "to do what one 'normally does' in those situations", what we "normally call '5"':

'If I have five, then I have three and two.' — But how do I know that I have five? -Well, if it looks like this: | | | | |. (WITTGENSTEIN, 1983, p. 61)

Wittgenstein's interlocutor is outraged. He misses the idea of a "mathematical operation" that fixes ahead the "correct" way of counting", quite independently of any empirical agent in any specific situation. In other words, he misses the idea of a "function".

Once again, we can resort to Frege on Wittgenstein' behalf, to German philosopher's idea of numerical attributions being “second order predications":

While looking at one and the same external phenomenon, I can say with equal truth both "It is a copse" and "It is five trees", or both "Here are four companies" and "Here are 500 men". Now, what changes here from one judgment to the other is neither any individual object, nor the whole, the agglomeration of them, but rather my terminology. ... This suggests as the answer ... that the content of a statement of number is an assertion about a concept. (FREGE, 1978, p. 59) 
Nothing in reality is "5". Even the dashes " | | | | |" in Wittgenstein passage could be seen as, say, an enormous number of "ink molecules", or an even greater number of atoms. Just as in the case of Frege's whale above, numbers do not talk (directly) about reality. Or, as Wittgenstein would say, they can talk about reality, but in this case there is nothing mathematical about them. The idea of a "correct, atemporal and impersonal, way to count" is just a "mythical idea" that should be laid aside.

\section{Connections between Wittgenstein's ideas and contemporary Mathematics and Philosophy}

We have presented, in broad brushstrokes, Wittgenstein's treatment of mathematical identities. But before we end this paper, let us quickly register what we believe are important connections between this treatment and more contemporary mathematical and philosophical literature.

The first link we would like to propose is mathematical, with the Theory of Categories of Mac Lane and Lawvere. Just as in Wittgenstein's case, the set theoretic concept of a function in extension is displaced by the metalinguistic concept of a morphism. For a category theorist, the best way to construe mathematical statements seems not so much to view them as talking about an ontology of (abstract) mathematical objects, but to step back and regard them from a metalinguistic perspective. His morphisms are not exactly functions (i.e., sets of pairs of objects), but establish metalinguistic invariants over structures. And just as in Wittgenstein's case, identity is somehow explained as isomorphism (back and forth morphisms).

The second and final connection we would like to propose is philosophical, with Quine's Thesis of the indeterminacy of Reference (QUINE, 1969, pp. Essays 1, 2) and his later concept of an "observational categorical" (QUINE, 1992, p. § 4). Right from the start, in his famous thought experiment of a linguist trying to recuperate a native's language, its lexicon and its grammar, we are invited by Quine to adopt a metalinguistic perspective. And, somewhat reminiscent of what happens in the theory of categories, his goal was to 
distinguish contents which remain invariant under radical translations and ones that fail to do so. (QUINE, 1960, p. § 7). Once again the result of this investigation is a skepticism towards the notion of "object": according to him, this semantical notion does not seem to be "stable" under radical translations (QUINE, 1960, p. § 12). At first, Quine's attention seemed to be directed to the negative thesis, the ones about the indeterminacy of reference (and of translation), but in his final years the philosopher proposed the more positive idea of an observational categorical. Again what we have is a kind of semantical connection between two concepts: "whenever this, that" (QUINE, 1992, p. 10). And again this is equated with the sole content which really remains invariant over remappings:

Translations does enjoy reasonable determinacy up through observational categorical and into logical connectives. Thus one could make a stab at the interlinguistic equating of empirical content even in radical translation. (QUINE, 1992, p. 52)

\section{References}

BAKER, G., \& HACKER, P. (1988). Wittgenstein: Rules, Grammar and Necessity. Oxford: Basil Blackwell.

BRADLEY, R. (1992). The Nature of All Being. Oxford: Oxford University Press.

DUMMETT, M. (1977). Elements of Intuitionism. Oxford: Clarendon Press.

DUmmeTT, M. (1991). The Logical Basis of Methaphysics. Cambridge: Harvard University Press.

DUMMETT, M. (1993). The Seas of Language. Oxford: Claredon Press.

DUMmeTT, M. (1978). Truth and Other Enigmas. Cambridge: Harvard University Press.

DUMmeTT, M. (1998). Truth from a Constructive Stanpoint. Theoria , LXIV, 122-38.

FRASCOLLA, P. (1994). Wittgenstein's Philosophy of Mathematics. Londres: Routledge.

FREGE, G. (1977a). Logical Investigations. Oxford: Basil Blackwell.

FREGE, G. (1964). The Basic Laws of Arithmetic. Berkeley: California University Press.

FREGE, G. (1978). The Foundations of Arithmetic. Oxford: Basil Blackwell. 
FREGE, G. (1977). Traslations from the Philosophical Writtings of Gottlob Frege. Oxford: Basil Blackwell.

GARDINER, A. (1982). Infinite Process: backgound to Analysis. New York: Springer-Verlag.

KRIPKE, S. (1972). Wittgenstein on Rules and Private Language. Oxford: Basil Blackwell.

MARION, M. (2008). Wittgenstein, Finitism and the Foundations of Mathematics. Oxford: Oxford University Press.

MARTIN-LÖF, P. (1991). A Path from Logic to Metaphysics. Atti del Congresso Nuovi problemi della Logica e della Filosofia dela Scienza. II, pp. 141-9. Bologna: CLUEB.

MARTIN-LÖF, P. (1979). Constructive Mathematics and Computer Science. VI International Congress for Logic, Methodology and Philosophy of Science (pp. 1-33). Hannover: Manuscript.

MARTIN-LÖF, P. (1984). Intuitionistic Type Theory. Napoles: Bibliopolis.

MARTIN-LÖF, P. (1996). On the Meanings of the Logical Constants and the Justifications of the Logical Laws. Nordic Journal of Philosophical Logic , I, pp. 11-60.

MARTIN-LÖF, P. (1995). Truth and Kwowability: On the Principles C and K of Michael Dummett. Second International Philosophy Conference of Mussomeli . Typescript.

MARTIN-LÖF, P. (1987). Truth of a propostion, Evidence fo a Judgement, validity of a Proof. Synthese, 73, pp. 407-420.

PARSONS, C. (1983). Mathematics into Philosophy. Ithaca: Cornell University Press.

PRAWITZ, D. (1977). The conflict between classical and Intuitionistic logic. Theoria , pp. 2-39.

PRAWITZ, D. (1998). Truth and Objectivity form a verificationist point of view. In: G. OLIVERI, \& H. DALES, Truth in Mathematics (pp. 4151). Oxford: Claredon Press.

QUINE, W. V. (1969). Ontological Relativity. In: W. V. QUINE, Ontological Relativity and Other Essays (pp. 26-68). Nova Iorque: Columbia University Press.

QUINE, W. V. (1992). Pursuit of Truth. Cambridge: Harvard.

QUINE, W. V. (1960). Word and Object. Cambridge: MIT.

SHANKER, S. (1987). Wittgenstein and the turning point in the Philosophy of Mathematics. Londres: Croom Helm.

SKÖLEM, T. (1952,). Sobre la Naturaleza do Razonamento Matemático. Gazeta Matemática , n 4, pp. 113-124. 
STENLUND, S. (1990). Language and Philosophical Problems. London: Routledge.

VAN HEIJENOORT, J. (1967). Form Frege to Gödel: a Source book in Mathematical Logic. Cambridge: Harvard University Press.

WAISMANN, F. (1979). Wittgenstein and the Viena Circle. Oxford: Basil Blackwell.

WEYL, H. (1963). Philosophy of Mathematics and Natural Science. Nova Iorque: Atheneum.

WITTGENSTEIN, L. (1976). Lectures on the Foundations of Mathematics Cambridge 1939. Chicago: Chicago Press.

WITTGENSTEIN, L. (2005a). Philosophical Investigations. Oxford: Basil Blackwell.

WITTGENSTEIN, L. (1993). Philosophical Occasions: 1912-1951. Cambridge: Hackett Publishing Company.

WITTGENSTEIN, L. (1975). Philosophical Remarks. Oxford: Basil Blackwell.

WITTGENSTEIN, L. (1983). Remarks on the Foundations of Mathematics. Cambridge: MIT.

WITTGENSTEIN, L. (2005). The Big Typescript. Oxford: Basil Blackwell.

WITTGENSTEIN, L. (1961). Tractatus Logico-Philosophicus. London: Routledge \& Kegan Paul.

WITTGENSTEIN, L. (1976). Wittgenstein's Lectures on the Foundations of Mathematics. (C. Diamond, Ed.) Hassocks: The Harvester.

WITTGENSTEIN, L. (1979). Wittgenstein's Lectures: Cambridge 1932-1935. Totowa: Roman \& Littlefield.

WITTGENSTEIN, L. (1979). Wittgenstein's Lectures: Cambridge 1932-1935. Totowa: Roman and Littlefield.

WRIGHT, C. (1993). Realism, Meangin and Truth. Oxford: Blackwell.

WRIGHT, C. (1980). Wittgenstein on the Foundations of Mathematics. Hampshire: Gower House. 